\title{
Ant workers exhibit specialization and memory during raft formation
}

\author{
Amaury Avril $^{1} \cdot$ Jessica Purcell $^{1,2} \cdot$ Michel Chapuisat $^{1}$
}

Received: 26 January 2016 /Revised: 17 March 2016 / Accepted: 26 March 2016

(C) Springer-Verlag Berlin Heidelberg 2016

\begin{abstract}
By working together, social insects achieve tasks that are beyond the reach of single individuals. A striking example of collective behaviour is self-assembly, a process in which individuals link their bodies together to form structures such as chains, ladders, walls or rafts. To get insight into how individual behavioural variation affects the formation of self-assemblages, we investigated the presence of task specialization and the role of past experience in the construction of ant rafts. We subjected groups of Formica selysi workers to two consecutive floods and monitored the position of individuals in rafts. Workers showed specialization in their positions when rafting, with the same individuals consistently occupying the top, middle, base or side position in the raft. The presence of brood modified workers' position and raft shape. Surprisingly, workers' experience in the first rafting trial with brood influenced their behaviour and raft shape in the subsequent trial without brood. Overall, this study sheds light on the importance of workers' specialization and memory in the formation of self-assemblages.
\end{abstract}

Keywords Self-assemblage $\cdot$ Collective behaviour · Task specialization $\cdot$ Rafting $\cdot$ Ants $\cdot$ Formicinae

Communicated by: Sven Thatje

Amaury Avril

amaury.avril@unil.ch

1 Department of Ecology and Evolution, Biophore, UNIL-Sorge, University of Lausanne, 1015 Lausanne, Switzerland

2 Present address: Department of Entomology, University of California, Riverside, 900 University Avenue, Riverside, CA 92521, USA

\section{Introduction}

Members of insect societies cooperate in sophisticated ways. By coordinating their actions and working collectively, workers manage to perform tasks that are beyond the reach of isolated individuals, such as transport large items (Detrain and Deneubourg 2008). On occasion, social insects link their bodies together to construct adaptive structures termed selfassemblages (Anderson et al. 2002). Self-assemblages take a variety of functional forms, such as bridges, bivouacs, protective curtains or rafts (Anderson et al. 2002; Reid et al. 2015).

The proximate mechanisms and behavioural processes involved in the formation of self-assemblages are poorly known (Anderson et al. 2002). Most self-assemblages described so far require quick reactions from colony members (Peeters and De Greef 2015; Reid et al. 2015). For instance, workers of the arboreal ant species Azteca andreae use an elaborate hunting technique: many workers self-assemble into 'pulling chain' structures to capture very large prey items, which requires fast coordination to prevent prey from escaping (Dejean et al. 2010). Researchers hypothesize that simple behavioural rules under positive feedback exponentially attract workers to the first individuals involved and therefore ensure a rapid growth of the self-assemblage (Foster et al. 2014; Garnier et al. 2013; Lioni et al. 2001). For example, Anderson and colleagues (2002) suggested that a rule such as 'run to the end of the chain and hang there' would be sufficient for Eciton ants to build structures such as chains or ladders. Hence, organized patterns arise from simple behavioural rules and individual decisions based on local information (Camazine et al. 2001).

Task specialization emerges when members of a social group consistently differ in their behavioural responses to a given input, and such division of labour is central to the organization of social insects colonies (Cahan and Gardner-Morse 2013; Ferrante et al. 2015; Holbrook et al. 2013). The 
specialization of individuals in performing particular tasks or roles tends to increase group efficiency (Beshers and Fewell 2001; Oster and Wilson 1978). In social insects, workers can display a wide array of specific tasks in colony defence, foraging or brood care (Rocha et al. 2014; Wilson 1980). Factors determining task specialization are numerous and include worker morphology, age, previous experience or genetic background (reviewed in Duarte et al. 2011). Extensive research has been carried out on task specialization and division of labour in insect societies (Smith et al. 2008). Yet, the role of task specialization in the construction of self-assemblages remains little explored, with only Eciton ants' bridges being investigated so far (Franks 1985; Garnier et al. 2013).

Here, we investigate the presence of specialization and the role of past experience in the construction of rafts by the Alpine silver ant Formica selysi. This species is found primarily in floodplains, where colonies may respond to floods by forming a living raft and floating to safety (Lude et al. 1999; Purcell et al. 2014). In a first experiment, we assess whether workers show specialization in the positions they occupy during the self-assembly of successive rafts. If workers uniformly follow a single set of assembly rules, we expect that they will be positioned at random in each raft. In contrast, if workers differ in their individual responses, they will consistently occupy similar positions in successive rafts. In a second experiment, we explore the effect of brood presence and prior experience by workers on raft assembly. Since brood is placed on the raft base (Purcell et al. 2014), we expect rafts with brood to have a different configuration than rafts with only workers. We then test for an effect of prior experience on raft assembly by removing brood for a second rafting trial. Together, these experiments describe individual behavioural variation in the formation of self-assemblages.

\section{Methods}

\section{Study system and apparatus}

F. selysi is a floodplain specialist living along rivers in the mountainous parts of central and southern Europe (Seifert 2002). When the rivers flood, this species can form floating rafts in both field (Lude et al. 1999) and laboratory conditions (Purcell et al. 2014). We collected workers and brood from 25 field colonies of $F$. selysi. All colonies come from a population located along the Rhône River, between Sierre and Susten in Valais, Switzerland $\left(7^{\circ} 36^{\prime} 30^{\prime \prime}\right.$ E, $4^{\circ} 18^{\prime} 30^{\prime \prime} \mathrm{N}$, altitude $565 \mathrm{~m}$ ). Groups of workers from each field colony were used in only one experiment, with each worker group being subjected to two successive rafting trials.

We mimicked natural floods using the apparatus described by Purcell et al. (2014). Briefly, we placed the ants on a raised watch glass mounted inside a plastic container and slowly increased the water level in the container. We recorded the positions of ants from above and below using two Logitech C905 webcams.

\section{Experiment 1-worker specialization in rafts}

We examined whether workers specialize on specific positions in raft assembly by subjecting the same groups of workers to two successive experimental floods and recording the positions of individuals in rafts. We formed 17 groups of 60 workers, with $20 \%$ of the workers marked with Lackmalstift ${ }^{\circledR}$ paint dots on the abdomen. Each marked worker had a unique combination of colours on both the ventral and dorsal faces. At least 3 days before the experiment, we returned the marked workers to their respective groups. We replaced marked individuals that died before the start of the experiment. After the experiment started, marked workers that died were not replaced. When they were not participating in rafting trials, groups were kept in plastic boxes with ad libitum access to water and standard ant food (Meunier and Chapuisat 2009). To initiate a rafting trial, we transferred each group to the watch glass of the apparatus and elicited raft formation by slowly increasing the water level. We considered groups to be rafting when the workers lost contact with the watch glass and were fully afloat. Three days after the first trial, we subjected the same groups to a second rafting trial.

Our analysis of worker positions in rafts began when the raft formed and began to float, and lasted for $30 \mathrm{~min}$ during each rafting bout. We recorded the amount of time spent by each focal worker at the base, middle, top and side positions (Fig. 1). We detected consistent inter-individual behavioural variation by comparing the proportion of time spent by workers in each of the four positions between the first and the second trials, as described in the statistical analysis section.

\section{Experiment 2-effects of brood presence and workers' prior experience on raft assembly}

We explored the effect of brood on raft assembly. As in experiment 1 , we subjected the ants to two successive floods and examined if workers show consistent positions across trials. However, in experiment 2, brood was added to the first raft trial and not to the second trial to further assess if individual position in the second trial depends on prior experience. In a previous study, we showed that brood is always placed at the bottom of the rafts in F. selysi, increasing the buoyancy of the rafts without any costs for brood survival (Purcell et al. 2014). We supplemented eight groups of 60 workers with 10 nestmate pupae. We marked $20 \%$ of the workers with paint and elicited raft formation as described above. For this analysis, we scored a single rafting position for each rafting session and each marked worker. In the rare cases where the focal worker moved from one position to another during the rafting 
Fig. 1 Schematic representation of an ant raft. Labelled workers depict base $(a)$, middle $(b)$, top $(c)$ and side $(d)$ positions

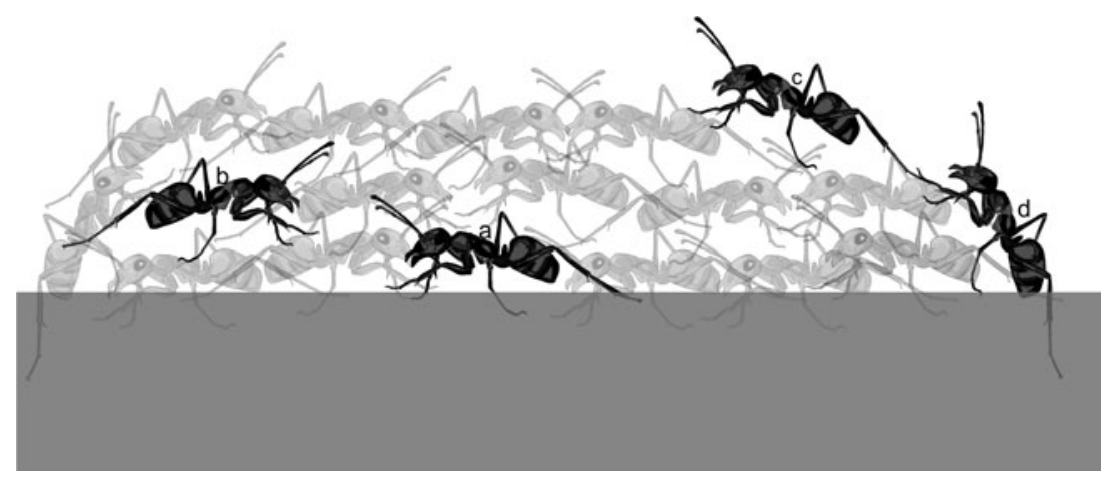

trial, we recorded the position that was occupied the longest. We assessed whether brood presence influenced raft configuration by comparing the proportion of workers in each position in rafts without brood and in rafts with brood, from the first trials of experiment 1 and 2, respectively.

To test if workers' prior experience influenced raft assembly, 3 days after the first rafting trial with pupae, we elicited a second raft with the same workers but without pupae. We scored the position of workers as described above. We compared the proportions of workers in each position in the first raft with brood and in the second raft without brood, from the first and second trials of experiment 2 , respectively.

\section{Statistical analysis}

We used permutation tests to distinguish between the null hypothesis that there would be no relationship between the positions of individually marked workers in the first and second flooding trial, and the alternate hypothesis, that marked workers would occupy the same position in successive rafts (robust gamma rank correlations with 10,000 permutations calculated in the R package 'rococo', $\mathrm{R}$ project software version 3.0.0, R Development Core Team 2015). This analysis examines whether the positions of the marked ants in the first trial are correlated with their positions in the second trial by comparing the correlation coefficient from the actual data with correlation coefficients obtained after permutating the identity of individually marked workers. Therefore, this test accounts for unequal proportions of marked workers in each position within each experiment. To control for multiple comparisons, we adjusted the alpha with a Bonferroni correction. To evaluate the effect of brood presence on raft configuration, we compared the proportion of marked workers in each position between the first trials of experiments 1 and 2 (without or with brood, respectively) using a chi-square test on the absolute number of marked workers. Based on a previous experiment (Purcell et al. 2014), we expected differences in the proportion of workers in each position in this initial raft. To test the effect of prior experience, we then compared the first and second trials of experiment 2 using a Wilcoxon signed rank test for paired data, in order to distinguish between our null hypothesis that the proportion of workers in each position would remain the same between trials, and our alternate hypothesis that the proportions would change in the absence of brood. We removed from our analyses marked workers that died between the two rafting trials.

\section{Results}

\section{Experiment 1-worker specialization in raft assembly}

Individual workers often occupied the same position in successive rafting trials. Specifically, workers that spent time on the top, middle, base or side of the first raft were significantly more likely to spend time in the same positions in the second raft (Table 1, Fig. 2a). Along the same lines, workers were significantly less likely to occupy a different position in the second trial in most cases (Table 1). The only exception to this pattern was occupancy of the base and side positions, which were positively correlated across successive rafting trials (Table 1). Eighty percent of the marked workers stayed in the same position for the 30 -min rafting duration. The numbers of moves for the same individual workers were not correlated between the first and second trial (correlation coefficient $\gamma=0.118, P=0.48$ ), suggesting that moving within the raft is not a specialized behaviour. Together, these results point

Table 1 Correlations between the positions of individual workers in the first and second raft (Experiment 1)

Position in the second raft Position in the first raft

\begin{tabular}{lllll}
\cline { 2 - 5 } & Base & Middle & Top & Side \\
\hline Base & $\mathbf{0 . 5 9 9 * *}$ & $-0.526^{* *}$ & $-0.394^{*}$ & $\mathbf{0 . 3 4 5 * *}$ \\
Middle & $-0.545^{* *}$ & $\mathbf{0 . 5 3 2 * *}$ & 0.259 & $-0.372^{* *}$ \\
Top & -0.337 & -0.103 & $\mathbf{0 . 3 7 7 *}$ & 0.006 \\
Side & $\mathbf{0 . 3 3 4 * *}$ & $-0.364^{* *}$ & -0.192 & $\mathbf{0 . 2 4 6}$ \\
\hline
\end{tabular}

Asterisks indicate significant robust gamma rank correlations with 10,000 permutations $(* P<0.05, * * P<0.01$, after Bonferroni correction). Positive and negative significant correlations are depicted in bold and italic, respectively 


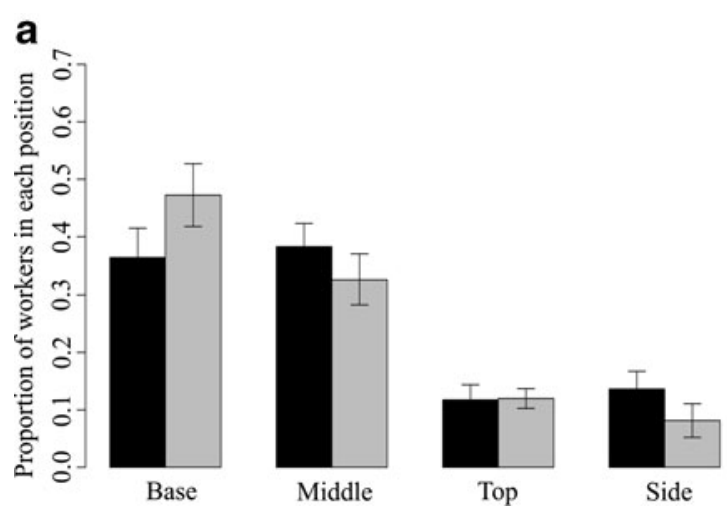

Fig. 2 Proportion of workers in each position during rafting. Black bars represent first trials and grey bars second trials. Error bars indicate $95 \%$ confidence intervals. a Experiment 1 . The groups of workers had no brood in the two successive trials ( $N=17$ colonies, $n=171$ workers). b

at consistent behavioural differences among workers in their positioning during self-assembly.

\section{Experiment 2-effects of brood presence and workers' prior experience on raft assembly}

The presence of brood influenced raft shape. Workers placed the brood at the base in all rafts, as previously documented (Purcell et al. 2014). The configuration of the raft, measured as the proportion of marked workers in each position, differed between first rafts without brood and first rafts with brood, as observed in the first trials of experiments 1 and 2, respectively (Fig. 2, chi-square test, $\chi_{(4)}^{2}=33.52, P<0.001$ ). Rafts with brood were flattened and contained fewer layers of workers than rafts without brood. As a result, rafts with brood had a larger proportion of workers occupying the base and top positions and a smaller proportion of workers occupying the middle and side positions, as compared to rafts without brood (Fig. 2).

Workers' prior experience had an effect on raft assembly. Indeed, workers without brood in the second trials of the two experiments formed rafts that differed significantly in their configuration, depending on whether brood was present (second experiment) or not (first experiment) in the first trial (Fig. 2a, b (grey bars), chi-square test, $\chi_{(4)}^{2}=37.05$, $P<0.001)$. The effect of past experience with brood was strong. In the second experiment, the configuration of the second raft without brood did not differ significantly from the configuration of the first raft when brood was present (Fig. 2b, Wilcoxon signed rank test, $V=3, P=1$ ).

\section{Discussion}

Workers often occupied the same raft positions in successive rafting trials, indicating inter-individual variation in assembly rules. Consistent inter-individual differences in decision rules

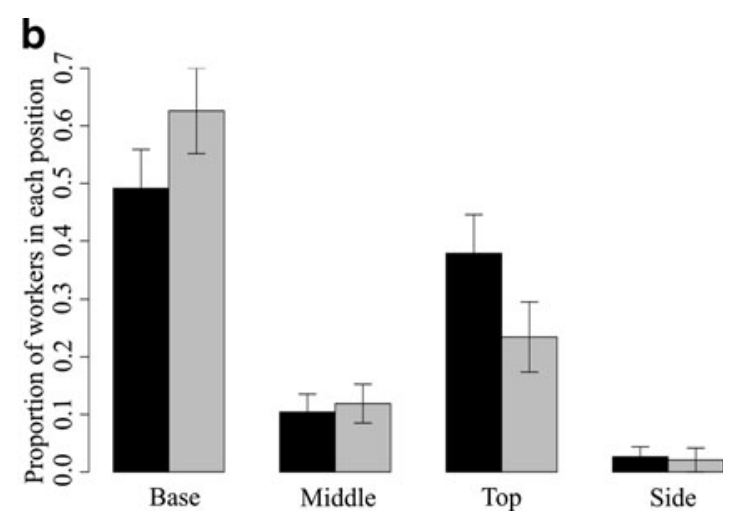

Experiment 2. The groups of workers had brood in the first trial (black bars) and no brood in the second trial (grey bars; $N=8$ colonies, $n=68$ workers)

have often been documented in animal societies (Jeanson and Weidenmuller 2014). Such variation generates adaptive division of labour (Beshers and Fewell 2001; Pruitt and Riechert 2011) and improves collective decisions (Dussutour et al. 2009; Jeanson et al. 2012). However, to our knowledge, specialization in the context of self-assemblages has only been demonstrated previously in Eciton ants, wherein morphologically distinct worker castes differ in their participation to bridge construction (Franks 1985; Garnier et al. 2013). Our study is the first to demonstrate individual specialization during self-assembly in an ant species that lacks discreet morphological worker castes. Models of self-organization consider that patterns emerge from simple behavioural rules on the basis of variation in local information (Camazine et al. 2001; Couzin and Krause 2003). Integrating inter-individual differences in these models should improve our understanding of the formation and function of self-assemblages (Jeanson et al. 2012).

We do not yet know which factors determine the consistent position of workers in the raft. Different positions may be associated with differences in behavioural castes, age and/or body size (Schwander et al. 2005). For example, workers on the base of the raft with brood may be nurses, while workers on top may be foragers. Foragers have a slightly larger body size than nurses in F. selysi (Schwander et al. 2005), and worker body size might also affect their placement in the raft. Along the same lines, the position of workers in bee swarms depended on their age, with younger bees tending to occupy the core of the swarm and older bees the mantle (Cully and Seeley 2004). Consistencies in worker positions may also result from different personalities among workers. Personality, i.e. consistent behavioural strategies through time and situations, has been documented across families of social insects (Jandt et al. 2013). In addition, behavioural group composition was shown to influence collective behaviour in ants (Cronin 2015; Hui and Pinter-Wollman 2014; Modlmeier et al. 2014) and social spiders (Pruitt and Riechert 2011). 
Further experiments involving different behavioural contexts are needed to determine whether consistency in worker position reflects individual personality, and whether variation in behavioural group composition affects raft formation.

The presence of brood influenced raft geometry and the positions of workers in the raft. Purcell et al. (2014) demonstrated that brood was always placed on the base of the rafts. Larvae and pupae improved the buoyancy of the rafts, and brood survival was not impaired by rafting (Purcell et al. 2014). Pupae and larvae are large items that have to be linked together by a number of workers at the base of the raft. These physical properties result in a flatter raft with a larger footprint. When brood is absent, rafts contain more layers and fewer individuals form the base. Therefore, having brood in the group constrains raft shape and workers' choice of positions, resulting in distinct raft configurations.

The presence of brood in a raft also influenced the configuration of subsequent rafts without brood. Specifically, the configuration of the second rafts, without brood, differed significantly between groups that had previously rafted with or without brood. Moreover, groups that rafted with brood in the first trial and without brood in the second trial assembled in rafts with similar configurations on both occasions. This result suggests that groups of workers have a form of memory, as their prior experience influences their behaviours in subsequent self-assemblages. Past experience affects how individuals behave in future interactions in many contexts (e.g. Grüter and Farina 2009; Liang et al. 2010; Ravary et al. 2007; Schwartz et al. 2007; Shah et al. 2010), but to our knowledge, memory had not been demonstrated in selfassemblages until now.

Workers rarely moved from one position to another when rafting in our experiment. This result contrasts with the high mobility of workers observed in much larger rafts of fire ants (Adams et al. 2011). A possible explanation is that worker behaviour during raft assembly varies with group size. In small rafts, workers would position themselves according to their individual specializations. When the number of workers reaches a certain threshold, workers would position themselves more randomly, ensuring a quick growth of the raft. In line with this argument, the behaviour of fire ant workers changed from linear to diffusive motion when the raft size increased (Mlot et al. 2012). In addition, an effect of group size on task specialization has been documented in multiple contexts. For instance, the complexity of the array of tasks performed increases at larger colony sizes in attine ants (Ferguson-Gow et al. 2014) and in Pogonomyrmex californicus (Holbrook et al. 2011). Moreover, the proportion of workers involved in different foraging tasks varies with colony size in Lasius niger (Mailleux et al. 2003). Further experiments involving variable raft size are needed to investigate whether behavioural rules during raft construction vary along with group size.
Together, these results shed light on the importance of inter-individual variation in collective behaviour. We demonstrated that workers assemble rafts according to their individual specialized position and past experience. The origin and adaptive value of individual variation in self-assemblages deserves further investigation.

Acknowledgments We thank Magalie Dialundama for her assistance in the lab, Emilie Lefoulon for the illustration of the ant raft, and Christoph Grüter, Adam L. Cronin and anonymous reviewers for comments on the manuscript. This project was funded by Swiss National Science Foundation grant 31003A-146641.

\section{Compliance with ethical standards}

Conflict of interest The authors declare that they have no conflict of interest.

\section{References}

Adams BJ, Hooper-Bùi LM, Strecker RM, O’Brien DM (2011) Raft formation by the red imported fire ant, Solenopsis invicta. J Insect Sci 11

Anderson C, Théraulaz G, Deneubourg J-L (2002) Self-assemblages in insect societies. Insect Soc 49:99-110

Beshers S, Fewell J (2001) Models of division of labor in social insects. Annu Rev Entomol 46:413-440

Cahan SH, Gardner-Morse E (2013) The emergence of reproductive division of labor in forced queen groups of the ant Pogonomyrmex barbatus. J Zool 291:12-22. doi:10.1111/jzo.12071

Camazine S, Deneubourg JL, Franks N, Sneyd J, Théraulaz G, Bonabeau E (2001) Self-organization in biological systems. In: Princeton University Press, Princeton

Couzin ID, Krause J (2003) Self-organization and collective behavior in vertebrates. Adv Study Behav 32:1-75

Cronin AL (2015) Individual and group personalities characterise consensus decision-making in an ant. Ethology 121:703-713. doi:10. 1111/eth. 12386

Cully SM, Seeley TD (2004) Self-assemblage formation in a social insect: the protective curtain of a honey bee swarm. Insect Soc 51: 317-324. doi: 10.1007/s00040-004-0743-3

Dejean A, Leroy C, Corbara C, Roux O, Céréghino R, Orivel J, Boulay R (2010) Arboreal ants use the "Velcro ${ }^{\circledR}$ Principle" to capture very large prey. PloS One 5. doi: 10.1371/journal.pone.0011331.g001

Detrain C, Deneubourg J-L (2008) Collective decision-making and foraging patterns in ants and honeybees. Adv Insect Physiol 35:123176

Duarte A, Weissing FJ, Pen I, Keller L (2011) An evolutionary perspective on self-organized division of labor in social insects. Annu Rev Ecol Evol Syst 42:91-110. doi:10.1146/annurev-ecolsys-102710145017

Dussutour A, Beekman M, Nicolis SC, Meyer B (2009) Noise improves collective decision-making by ants in dynamic environments. Proc R Soc B 276:4353-4361. doi:10.1098/rspb.2009.1235

Ferguson-Gow H, Sumner S, Bourke AF, Jones KE (2014) Colony size predicts division of labour in attine ants. Proc Biol Sci 281. doi: 10. 1098/rspb.2014.1411 
Ferrante E, Turgut AE, Duéñez-Guzmán E, Dorigo M, Wenseleers T (2015) Evolution of self-organized task specialization in robot swarms. PLoS Comput Biol 11. doi: 10.1371/journal.pcbi.1004273

Foster PC, Mlot NJ, Lin A, Hu DL (2014) Fire ants actively control spacing and orientation within self-assemblages. J Exp Biol 217: 2089-2100. doi:10.1242/jeb.093021

Franks NR (1985) Reproduction, foraging efficiency and worker polymorphism in army ants. Fortschr Zool 31:91-107

Garnier S, Murphy T, Lutz M, Hurme E, Leblanc S, Couzin ID (2013) Stability and responsiveness in a self-organized living architecture. PLoS Comput Biol 9:e1002984. doi:10.1371/journal.pcbi.1002984

Grüter C, Farina WM (2009) Past experiences affect interaction patterns among foragers and hive-mates in honeybees. Ethology 115:790 797. doi:10.1111/j.1439-0310.2009.01670.x

Holbrook CT, Barden PM, Fewell JH (2011) Division of labor increases with colony size in the harvester ant Pogonomyrmex californicus. Behav Ecol 22:960-966. doi:10.1093/beheco/arr075

Holbrook CT, Fewell JH, Kukuk PF (2013) Increased group size promotes task specialization in a normally solitary halictine bee. Behaviour 1-18 doi: 10.1163/1568539x-00003104

Hui A, Pinter-Wollman N (2014) Individual variation in exploratory behaviour improves speed and accuracy of collective nest selection by Argentine ants. Anim Behav 93:261-266. doi:10.1016/j.anbehav. 2014.05.006

Jandt JM, Bengston S, Pinter-Wollman N, Pruitt JN, Raine NE, Dornhaus A, Sih A (2013) Behavioural syndromes and social insects: personality at multiple levels. Biol Rev Camb Philos Soc 89:48-67. doi:10. 1111/brv. 12042

Jeanson R, Weidenmuller A (2014) Interindividual variability in social insects - proximate causes and ultimate consequences. Biol Rev Camb Philos Soc 89:671-687. doi:10.1111/brv.12074

Jeanson R, Dussutour A, Fourcassie V (2012) Key factors for the emergence of collective decision in invertebrates. Front Neurosci 6:121. doi:10.3389/fnins.2012.00121

Liang SH, Lin WY, Lin YC, Chen YC, Shieh BS (2010) Variations in the pit size of Cueta sauteri (Neuroptera: Myrmeleontidae) larvae in response to past pit-building experience and food limitation. Zool Stud 49:102-107

Lioni A, Sauwens C, Theraulaz G, Deneubourg J-L (2001) Chain formation in Oecophylla longinoda. J Insect Behav 14:679-696. doi:10. 1023/A:1012283403138

Lude A, Reich M, Plachter H (1999) Life strategies of ants in unpredictable floodplain habitats of Alpine rivers (Hymenoptera: Formicidae). Entomol Gen 24:75-91

Mailleux A-C, Deneubourg J-L, Detrain C (2003) How does colony growth influence communication in ants? Insect Soc 50:24-31.

Meunier J, Chapuisat M (2009) The determinants of queen size in a socially polymorphic ant. J Evol Biol 22:1906-1913. doi:10.1111/ j.1420-9101.2009.01805.x

Mlot NJ, Tovey C, Hu DL (2012) Dynamics and shape of large fire ant rafts. Commun Integr Biol 5:590-597. doi:10.4161/cib.21421
Modlmeier AP, Keiser CN, Shearer TA, Pruitt JN (2014) Species-specific influence of group composition on collective behaviors in ants. Behav Ecol Sociobiol 68:1929-1937. doi:10.1007/s00265-014-1799-3

Oster GF, Wilson EO (1978) Caste and ecology in the social insects. Monographs in population biology, vol 12. Princeton University Press, Princeton NJ

Peeters C, De Greef S (2015) Predation on large millipedes and selfassembling chains in Leptogenys ants from Cambodia. Insect Soc 62:471-477. doi:10.1007/s00040-015-0426-2

Pruitt JN, Riechert SE (2011) How within-group behavioural variation and task efficiency enhance fitness in a social group. Proc R Soc B 278:1209-1215. doi:10.1098/rspb.2010.1700

Purcell J, Avril A, Jaffuel G, Bates S, Chapuisat M (2014) Ant brood function as life preservers during floods. PLoS ONE 9. doi: 10.1371/ journal.pone.0089211.g001, 10.1371/journal.pone.0089211.g002

R Development Core Team (2015) R: a language and environment for statistical computing. R Foundation for Statistical Computing, Vienna

Ravary F, Lecoutey E, Kaminski G, Chaline N, Jaisson P (2007) Individual experience alone can generate lasting division of labor in ants. Curr Biol 17:1308-1312. doi:10.1016/j.cub.2007.06.047

Reid CR, Lutz MJ, Powell S, Kao AB, Couzin ID, Garnier S (2015) Army ants dynamically adjust living bridges in response to a costbenefit trade-off. Proc Natl Acad Sci U S A 112:15113-15118. doi: $10.1073 /$ pnas. 1512241112

Rocha FH, Lachaud J-P, Valle-Mora J, Pérez-Lachaud G, Zeh D (2014) Fine individual specialization and elitism among workers of the ant Ectatomma tuberculatum for a highly specific task: intruder removal. Ethology 120:1185-1198. doi:10.1111/eth.12291

Schwander T, Rosset H, Chapuisat M (2005) Division of labour and worker size polymorphism in ant colonies: the impact of social and genetic factors. Behav Ecol Sociobiol 59:215-221. doi:10. 1007/s00265-005-0027-6

Schwartz AM, Baird TA, Timanus DK (2007) Influence of age and prior experience on territorial behavior and the costs of defense in male collared lizards. Ethology 113:9-17. doi:10.1111/j.1439-0310.2006. 01297.x

Seifert B (2002) A taxonomic revision of the Formica cinerea group (Hymenoptera: Formicidae). Abh Ber Naturkundemuseum Görlitz 74:245-272

Shah AA, Ryan MJ, Bevilacqua E, Schlaepfer MA (2010) Prior experience alters the behavioral response of prey to a nonnative predator. J Herpetol 44:185-192. doi:10.1670/09-025.1

Smith CR, Toth AL, Suarez AV, Robinson GE (2008) Genetic and genomic analyses of the division of labour in insect societies. Nat Rev Genet 9:735-748. doi:10.1038/nrg2429

Wilson EO (1980) Caste and division of labor in leaf-cutter ants (Hymenoptera: Formicidae: Atta). I. The overall pattern in A. sexdens. Behav Ecol Sociobiol 7:143-156 